\title{
Computational design of accelerated life testing applied to frozen green beans
}

\author{
R.C. Martins, C.L.M. Silva* \\ Escola Superior de Biotecnologia, Universidade Católica Portuguesa, Rua Dr. António Bernardino de Almeida, 4200-072 Porto, Portugal
}

Keywords: Accelerated life testing; Frozen stored foods; Kinetics quantification; Simulation; Green beans

\begin{abstract}
Three different accelerated life tests (ALT) were designed by computer simulation to investigate their practical applicability to quantify kinetics of quality loss in frozen stored foods. Heat transfer and quality degradation inside a green bean were simulated, using a spectral finite element method (SFEM), to develop pseudo-experimental data. Temperature fluctuations inside a refrigerator were simulated, by a piecewise linear stochastic differential equation, and integrated into the SFEM program. Thereafter, the simulated data was treated by non-linear regression analysis to estimate the kinetic parameters. The different ALT tests were then compared in terms of precision and accuracy.

This study shows that temperature fluctuations, inside a refrigerator, influence the accuracy of the kinetic estimates, and if the temperature spectrum is used to derive kinetic estimates, it is possible to apply accurately ALT methodologies to frozen foods.
\end{abstract}

\section{Introduction}

Slow reaction rates and long storage times have been the major hurdles of frozen foods isothermal kinetics studies. The time involved in these type of experiments is exorbitant. For example, data must be collected over a minimum period of 6-12 months, at temperatures of -7 to $-30{ }^{\circ} \mathrm{C}$, or even lower temperatures.

Accelerated life testing (ALT) techniques have been developed as an engineering tool to reduce this experimental time. ALT were originally developed for reliability studies of long lasting events (e.g. mechanical failure of engine parts, hardware failure, control failure of nuclear reactors), and proved to be a very effective tool for product development (Høyland \& Rausand, 1994). By estimating product's failures, corrections and improvements can be done quickly.

ALT techniques have been used to estimate shelf life of foods. The most generally accepted methodology is to expose foods to controlled overstress conditions (e.g.

\footnotetext{
${ }^{*}$ Corresponding author. Tel.: +351-22-5580058; fax: +351-225090351.

E-mail addresses: r.m.c.m@clix.pt (R.C. Martins), crislui@esb.ucp.pt (C.L.M. Silva).
}

high temperatures, low $\mathrm{pH}$ and high $\mathrm{a}_{\mathrm{w}}$ ) to reduce the 'mean time to failure'. Thereafter, shelf life is extrapolated into normal conditions of storage and distribution, using the fitted models.

In early ALT methods for foods (Labuza \& Schimdl, 1985; Ragnarsson \& Labuza, 1977; Waletzko \& Labuza, 1976), a reduced number of storage experiments were made at two constant elevated temperatures to determine kinetic rates and the Arrhenius activation energy. Then, kinetic rates were extrapolated to lower storage temperatures.

Extrapolation increases the uncertainty of predicted data, especially if the tested range is narrow (Bates \& Watts, 1988; Box, Hunter, \& Hunter, 1978; Neter, Kutner, Nachtsheine, \& Wasserman, 1996). To overcome this difficulty, Reid (1999) proposed use of the glass transition temperature $\left(T_{\mathrm{g}}^{\prime}+5^{\circ} \mathrm{C}\right)$ as an extra regression point. It was assumed that the Arrhenius law is observed above the glass transition temperature. However, a number of quality degradation reactions are not so dependent on phase transitions. For example, oxidation by molecular oxygen, which has a high mobility below the glass transition temperature.

Frozen foods are stored at temperatures higher than $-25{ }^{\circ} \mathrm{C}$, and generally are distributed near the limit of the legal temperature $\left(-18{ }^{\circ} \mathrm{C}\right.$ for most countries), i.e. at 


\begin{tabular}{|c|c|c|c|}
\hline \multicolumn{4}{|c|}{ Nomenclature } \\
\hline$\alpha$ & autoregressive process parameter & Er & average absolute error \\
\hline$\lambda$ & thermal conductivity, $\mathrm{W} \mathrm{m}^{-1} \mathrm{~K}^{-1}$ & $f$ & force vector, W \\
\hline$\nabla$ & divergence operator & $h$ & surface heat transfer coefficient, $\mathrm{W} \mathrm{m}^{-2} \mathrm{~K}^{-1}$ \\
\hline$\Omega$ & physical domain & $k$ & kinetic rate, day $^{-1}$ \\
\hline & autoregressive process parameter (discrete & $K$ & stiffness matrix, $\mathrm{W} \mathrm{K}^{-1}$ \\
\hline & form) & $n$ & normal to the surface boundary \\
\hline & density, $\mathrm{kg} \mathrm{m}^{-3}$ & $R$ & universal gas constant, $\mathrm{J} \mathrm{mol}^{-1} \mathrm{~K}^{-1}$ \\
\hline$\sigma^{2}\{c\}$ & quality value variance-covariance matrix & SE & regression standard error \\
\hline$\sigma^{2}\{u\}$ & temperature variance-covariance matrix & $t$ & time, $\mathrm{s}$ \\
\hline & $\begin{array}{l}\text { autoregressive process parameter (discrete } \\
\text { form) }\end{array}$ & $\begin{array}{l}u \\
w(t)\end{array}$ & $\begin{array}{l}\text { temperature, } \mathrm{K} \\
\text { independent gaussian error source }\end{array}$ \\
\hline & autoregressive noise at time $t$ & \multicolumn{2}{|c|}{ Subscripts } \\
\hline ARMA & autoregressive moving average model & $\begin{array}{l}\text { Subs } \\
\infty\end{array}$ & $\begin{array}{l}\text { pts } \\
\text { environment }\end{array}$ \\
\hline & autoregressive process parameter & $\begin{array}{l}\infty \\
0\end{array}$ & initial condition \\
\hline$C$ & capacitance matrix, $\mathrm{J} \mathrm{K}^{-1}$ & $\begin{array}{l}0 \\
d\end{array}$ & deterministic value \\
\hline & the quality parameter value at time $t$ & eq & at the equilibrium \\
\hline & heat capacity, $\mathrm{J} \mathrm{kg}^{-1} \mathrm{~K}^{-1}$ & $\begin{array}{l}\text { eq } \\
\text { ref }\end{array}$ & at the reference temperature \\
\hline$E\{c\}$ & expected average quality value & 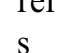 & at the surface \\
\hline$E\{u\}$ & expected average nodal temperature, $\mathrm{K}$ & $\begin{array}{l}\mathrm{s} \\
t\end{array}$ & \\
\hline & Arrhenius activation energy, $\mathrm{J} \mathrm{mol}^{-1}$ & & \\
\hline
\end{tabular}

temperatures higher than $T_{\mathrm{g}}^{\prime}$. In this temperature range, the Ahrrenius law agrees with experimental data, obtained after selected isothermal experiments.

Non-isothermal methodologies used in the pharmaceutical industry have been applied in food research, but not in the area of frozen storage. Some of these food studies use a linear temperature increase with the experimental time, covering the needed temperature range to estimate kinetic parameters (Brandão \& Oliveira, 1997; Frias, 1998; Moreira, Oliveira, Silva, \& Oliveira, 1993; Rhim, Nunes, Jones, \& Swartzel, 1989a, 1989b). Experiments and simulations were made to optimise this technique, increasing the accuracy and precision in the estimated parameters (Brandão \& Oliveira, 1997). However, results are unsatisfactory when $5 \%$ error in concentration occurs, and a larger number of samples has to be taken compared to isothermal experiments. This is the case for most food quality parameters (Labuza, 2000).

The frozen food industry applies a more practical approach. Often, frozen foods are subjected to a number of freeze-thaw cycles, and the number of cycles at which quality degradation is evident is determined. Shelf life is 'extrapolated' to normal storage and distribution conditions on empirical basis (Reid, Kotte, \& Kilmartin, 1999). This test is preferred for practical reasons, but utilises a subjective interpretation of product's shelf life. Furthermore, the 'extrapolation' requires previous knowledge of similar products, specially their sensory attributes and consumer's reaction, because degradation kinetics are not taken into account along with storage and distribution conditions, and this technique is of little use for the development of inovative products.

In conclusion, two main difficulties exist in the design of frozen foods quality loss experiments: (i) long experimental times, and (ii) temperature fluctuations inside a refrigerator. The second issue is particularly relevant, because thermal fluctuations accelerate quality losses and decrease the accuracy with which kinetic parameters can be estimated, especially if a constant temperature is assumed during regression analysis.

Dynamic ALT tests may overcome this problem, as they take into account the temperature fluctuations during the optimisation procedure. Under dynamic testing, time, temperature and the quality parameter must be continuously evaluated at regular time intervals. For example, both time and temperature can be measured with a data logger device, whereas, carefully planned quality measurements must be obtained over the experimental time. Thereafter, time and temperature histories are used as variables in the expected integrated kinetic law, and kinetic parameters are optimised.

Because ALT methodologies applied to frozen food research are still in their infancy, the objectives of this research study were to:

(i) Demonstrate the potentialities of three ALT techniques, by computer simulation; (ii) compare the proposed ALT techniques with the previous ALT methodologies; (iii) derive conclusions on how quality degradation kinetics of frozen stored foods should be obtained. 


\section{Materials and methods}

\section{Green beans quality studies}

Green beans (Phaseolus vulgaris L.) quality losses were previously studied along 250 days of storage at -7 , -15 and $-30{ }^{\circ} \mathrm{C}$ (Martins \& Silva, 2002, 2003a, 2003b). These studies aimed at recording losses of vitamin $\mathrm{C}$, colour, chlorophylls, starch, reducing sugars and changes in texture versus storage time, at the three different temperatures, in order to obtain their degradation kinetics by an 'isothermal' method. Flavour difference kinetics was obtained from Labuza (1982). These studies concluded that there is a large deviation in terms of temperature sensitivity of quality factors degradation kinetics. Nutritional parameters are less retained by low storage temperatures, than sensory parameters that are very well retained at low storage temperatures (e.g. -30 $\left.{ }^{\circ} \mathrm{C}\right)$. Table 1 presents the three most representative quality loss kinetics in terms of temperature sensitivity. Ascorbic acid loss and total vitamin $\mathrm{C}$ losses, and flavour difference have, respectively, low, intermediate and high sensitivity to temperature. Therefore, in this study these were considered representative of the quality losses spectrum.

\section{Heat transfer model}

A two-dimensional stochastic finite element method (SFEM) was written in $\mathrm{C}++$ language (Barton \& Nackman, 1991; Meyers, 1998). Because stochastic algorithms lead to considerable computational load, the SFEM code was changed to run on a distributed architecture, using the Parallel Virtual Machine C library code (Geist et al., 1994). Simulations were let to run in a LINUX Beowulf class cluster (Almeida \& Martins, 2001). Fig. 1 presents the SFEM mesh used to simulate axial heat transfer on a green bean inserted in an expanded polyethylene platform.

During the development of the heat transfer model the following assumptions were made:

- Heat transfer inside the green bean is only by conduction, and on the exposed surface by convection. The value of $h$ was assumed to be $12 \mathrm{~W} \mathrm{~m}^{-2} \mathrm{~K}^{-1}$ at the surface mesh, with no local variations;

- Heat capacity $\left(C_{p}=1004 \mathrm{~J} \mathrm{~kg}^{-1} \mathrm{~K}^{-1}\right)$ and heat conductivity $\left(\lambda=0.08 \mathrm{~W} \mathrm{~m}^{-1} \mathrm{~K}^{-1}\right)$ of the air elements, in the physical domain $(\Omega)$, are constant both in time and space;

- Product heat capacity and heat conductivity evolution with temperature were modeled independently, by fitting to experimental data the Schwartzberg (1976), modified by Ramaswamy and Tung (1981), and Schwartzberg (1981) equations, respectively. The parameters of the mentioned equation were obtained from Martins and Silva (2003b). These heat transfer properties were implemented stochastically using a spectral approach (Ghanem, 1991), so that the biological variability can be taken into account;

- Heat production and latent heat loss, due to mass transfer, is negligible;

- The expanded polyethylene heat diffusion is negligible, when compared to air or green beans.

Given these assumptions, the temperature at any point of $\Omega(u)$ can be described by the Fourier law in the conservative form (Ozisik, 1994; Shashkov, 1996):

$\rho C_{p} \frac{\partial u}{\partial t}=\nabla(\lambda \nabla u)$

With the initial condition:

$u(\Omega)=u_{0} \quad$ and $\quad t=t_{0}$

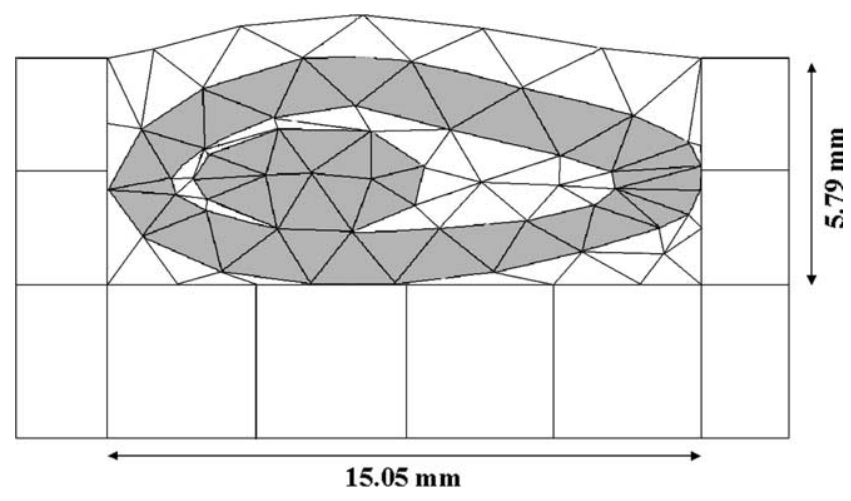

Fig. 1. Green beans finite elements mesh.

Table 1

Quality loss kinetic parameters

\begin{tabular}{lccl}
\hline Quality parameter & Ascorbic acid $\left(\mathrm{mg} 100 \mathrm{~g}^{-1}\right)^{\mathrm{a}}$ & Vitamin $\mathrm{C}\left(\mathrm{mg} 100 \mathrm{~g}^{-1}\right)^{\mathrm{a}}$ & ${\text { Flavour difference }(\%)^{\mathrm{b}}}$ \\
\hline$c_{0}$ & 146.1 & 146.1 & 100 \\
$k_{\mathrm{ref}} \times 10^{-2}\left(\mathrm{day}^{-1}\right)^{\mathrm{c}}$ & 15.61 & 3.226 & 7.769 \\
$E_{\mathrm{a}}\left(\mathrm{kJ} \mathrm{mol}^{-1}\right)$ & 3.861 & 42.01 & 117 \\
$\mathrm{SE}$ & 8.565 & 8.565 & 5.000 \\
\hline
\end{tabular}

${ }^{\mathrm{a}}$ Data from Martins and Silva (2002, 2003a).

${ }^{\mathrm{b}}$ Data from Dietrich et al. (1959), referred by Labuza (1982).

${ }^{\mathrm{c}} u_{\mathrm{ref}}=-15^{\circ} \mathrm{C}$. 
where $u_{0}$ is the initial temperature at $t_{0}$, the instant zero, and at the surface boundaries of $\Omega$ :

$\lambda \frac{\partial u}{\partial n}=h \cdot\left(u_{\infty}-u_{\mathrm{s}}\right)$

where $n$ is the normal to the surface boundary, $h$ the surface heat transfer coefficient, $u_{\infty}$ the environmental temperature and $u_{\mathrm{s}}$ the surface temperature.

The finite element method (FEM) approximates the green beans physical domain by a mesh of finite elements, connecting points in space called nodes (Henwood \& Bonet, 1996). In each triangular element, temperature is approximated by a linear relationship between nodal temperatures (Braess, 1997). The final solution to the 2nd Fourier law is reduced to the following linear differential equation (Segerlind, 1984):

$C \frac{\partial u}{\partial t}+K u=f$

where $C$ is the capacitance matrix, expressing the volumetric heat capacitance, $K$ is the stiffness matrix, which includes heat conduction and convection effects on nodal temperatures, and $f$ is the force vector, that expresses the influence of ambient temperature on nodal temperatures. Nodal temperature evolution can be calculated using a finite difference scheme, such as the CrankNicholson.

The SFEM approach generates different heat transfer properties spectrum over time and space (Ghanem, 1991). Thus, the SFEM solves the temperature at every nodal point, for each stochastic spectrum of heat transfer properties.

Therefore, Eq. (4) has to be solved for each one of the $i$ possible independent thermal properties $\left(\lambda\right.$ and $\left.C_{p}\right)$ on that time interval:

$C^{i} \frac{\partial u^{i}}{\partial t}+K^{i} u^{i}=f^{i}$

Thereafter, the expected nodal temperature is given by its average value $(E\{u\})$. The variance-covariance matrix of the solution can be also calculated:

$\sigma^{2}\{u\}=\left[u^{i}-E\{u\}\right] \cdot\left[u^{i}-E\{u\}\right]^{\mathrm{T}}$

where the nodal temperatures variance is obtained as the diagonal elements of $\sigma^{2}\{u\}$ (Ghanem, 1991).

Therefore, the model is capable to generate, for a given time interval, the expected temperature, its variance and the covariance between nodal temperatures.

\section{Quality loss simulation}

All the selected quality parameters (see Table 1) were successfully modeled by a first order model, using the one step optimisation procedure (Arabshahi \& Lund, 1985): $\frac{\mathrm{d} c}{\mathrm{~d} t}=-k_{\mathrm{ref}} \cdot \exp \left[-\frac{E_{\mathrm{a}}}{R} \cdot\left(\frac{1}{u(\Omega)}-\frac{1}{u_{\mathrm{ref}}}\right)\right] \cdot C+w(t)$

where $c$ is the quality parameter, $k_{\text {ref }}$ the kinetic rate at the reference temperature $u_{\text {ref }}, E_{\mathrm{a}}$ the Arrhenius activation energy, $R$ the universal gas constant and $w(t)$ the independent gaussian error as the stochastic source.

The quality degradation kinetics was implemented with the SFEM heat transfer model, using the following assumptions:

- Nutrients diffusion is negligible.

- The degradation rate is space independent.

- Degradation rate, at a given node of $\Omega$, is only dependent on temperature $u(\Omega)$, and it is given by the Arrhenius law.

For each time-temperature spectrum, quality loss is calculated for the entire physical domain and at the nodal positions. Therefore, the average value and variance of each quality loss parameter at a nodal position can also be estimated by the calculation of the variance covariance matrix.

However, quality parameters, such as vitamin $\mathrm{C}$, are measured experimentally by destructive tests. Therefore, it is not possible to quantify quality losses experimentally at specific nodal points, and an average value per sample volume is computed for the green bean model. Both first and second statistical moments can be calculated. It is possible to obtain the average quality loss and standard deviation across the physical domain by Eqs. (8) and (9), respectively:

$E\{c\}=\frac{\int_{\Omega} c \mathrm{~d} \Omega}{\Omega}$

$\sigma^{2}(c)=\frac{\int_{\Omega}(c-E\{c\})^{2} \mathrm{~d} \Omega}{\Omega}$

\section{Refrigerator temperature spectrum}

It is generally accepted that during storage studies the temperature inside a refrigerator remains constant. However, food inside domestic freezers exhibit temperature fluctuations as much as $\pm 5{ }^{\circ} \mathrm{C}$, with a frequency between 0.25 and 3 cycles per hour (Giel, 1998).

Home freezers are built to reduce manufacture and energy costs, and are not designed to maintain a constant temperature. The refrigerator's thermostat is very simple. When temperature goes above a maximum value, the compressor switches on. After the air temperature has decreased below the minimum temperature, the compressor switches off. The main reason for this type of control is to maximise the time in the off position. By reducing the compressor work load, the 
freezer cost is simply decreased, by using smaller compressors (Giel, 1998).

Thermal fluctuations inside a refrigerator can be regarded mathematically as a stable limit cycle, where temperature undergoes a defined observable periodic oscillation, and fluctuates around a central area on a phase diagram. Physically, limit cycles represent the dynamic stationary state of sustained oscillations, which does not depend on initial conditions, but depend exclusively on the system parameters (Tong, 1994).

This kind of physical dynamical behaviour can be divided into two phases: (I) when the compressor is on and (II) when the compressor is off (see Fig. 2). In each region, it is possible to described the system's dynamics by a linear stochastic differential equation:

$$
\begin{aligned}
& \frac{\mathrm{d}^{n}}{\mathrm{~d} t^{n}} u_{\infty}(t)+\alpha_{n-1} \frac{\mathrm{d}^{n-1}}{\mathrm{~d} t^{n-1}} u_{\infty}(t)+\cdots+\alpha_{0} u_{\infty}(t) \\
& \quad=b_{n-1} \frac{\mathrm{d}^{n-1}}{\mathrm{~d} t^{n-1}} w(t)+\cdots+b_{1} \frac{\mathrm{d}}{\mathrm{d} t} w(t)+w(t)
\end{aligned}
$$

This equation is called a continuous autoregressive moving average model, $\operatorname{AM}(n, n-1)$ (Pandit \& $\mathrm{Wu}$, 1983). However, it is possible to show that when a continuous stochastic system, described by Eq. (10), is sampled at constant time intervals, the observed data can be represented in the discrete form:

$$
\begin{aligned}
u_{t} & -\phi_{1} u_{t-1}-\cdots-\phi_{n} u_{t-n} \\
& =a_{t}-\theta_{1} a_{t-1}-\cdots-\theta_{n-1} a_{t-n+1}
\end{aligned}
$$

This linear stochastic difference equation is known as the discrete Autoregressive Moving Average model, $\operatorname{ARMA}(n, n-1)$, and the coefficients of this difference equation can be obtained by regression analysis. Therefore, for each On/Off phase, it is possible to obtain

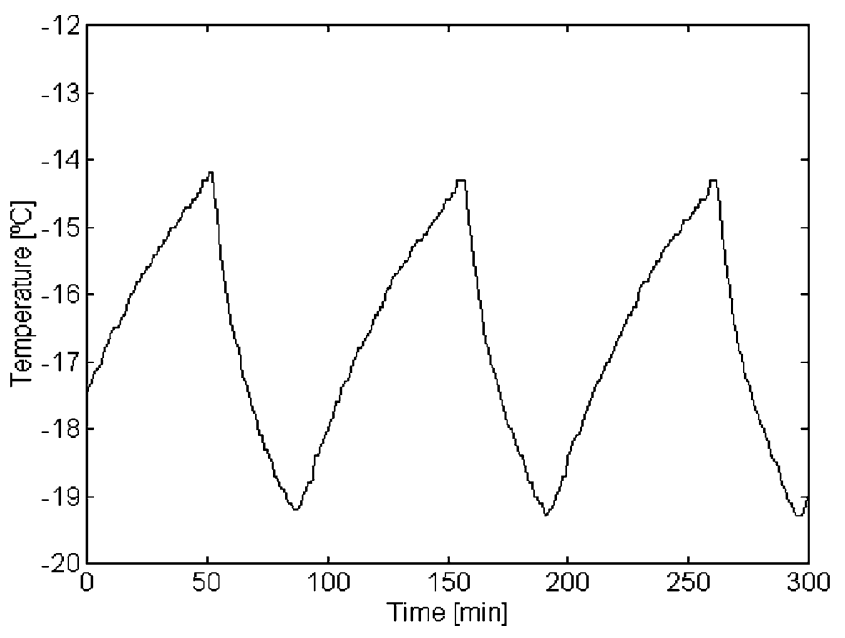

Fig. 2. Refrigerator time-temperature spectrum. an $\operatorname{ARMA}(n, n-1)$ model, which describes the system dynamics.

It is also necessary to model the $u_{\infty}$ versus $t$ curves (see Fig. 2). A linear regression analysis was made to model the maximum and minimum temperature limits with the thermostat position.

\section{Accelerated life testing}

The experimental ALT designs were divided into three categories: designs I, II and III. An illustrative example is presented in Fig. 3.

\section{Design I}

Three samples were put into three refrigerators, set to the average thermostat temperature of $-5,-7$ and -15 ${ }^{\circ} \mathrm{C}$, for 24,25 and 30 days, respectively. Simulated temperature and quality losses data were recorded every minute to an output buffer file.

\section{Design II}

Green beans were subjected to consecutive increases in temperature, by step levels. The design expects an average of $25 \%$ quality degradation for each stress level. Thus, the same sample is exposed for 15, 7, 6 and 5 days at the average thermostat temperature of $-30,-20,-10$ and $-5^{\circ} \mathrm{C}$, respectively.

\section{Design III}

A linear increase in the average thermostat position was set up in this simulation. The temperature set-up increased linearly from -30 to $-5{ }^{\circ} \mathrm{C}$, at a rate of 0.758 ${ }^{\circ} \mathrm{Cday}^{-1}$.

\section{Data analysis Design I}

Non-linear regression analysis for model fitting was performed on all data, in a one-step optimisation procedure (Arabshahi \& Lund, 1985), by maximising the likelihood function for all the three temperatures to the isothermal kinetic equation:

$c=c_{0} \cdot \exp \left(-k_{\mathrm{ref}} \cdot \exp \left[-\frac{E_{\mathrm{a}}}{R} \cdot\left(\frac{1}{u}-\frac{1}{u_{\mathrm{ref}}}\right)\right] \cdot t\right)$

The kinetic parameters of Eq. (12) were estimated for the quality attributes ascorbic acid, total vitamin $\mathrm{C}$ and flavour difference. A computer program was developed with the $\mathrm{C}++$ language using the BLITZ++ Library $\mathrm{C}++$ code (Veldhuizen, 1999), with the Gauss-Newton optimisation algorithm to solve the normal equations and determine the parameter estimates. The estimated parameter's variance was obtained by the variancecovariance matrix of the regression coefficients, and the model standard deviation was estimated by the mean standard error (Bates \& Watts, 1988; Neter et al., 1996). 

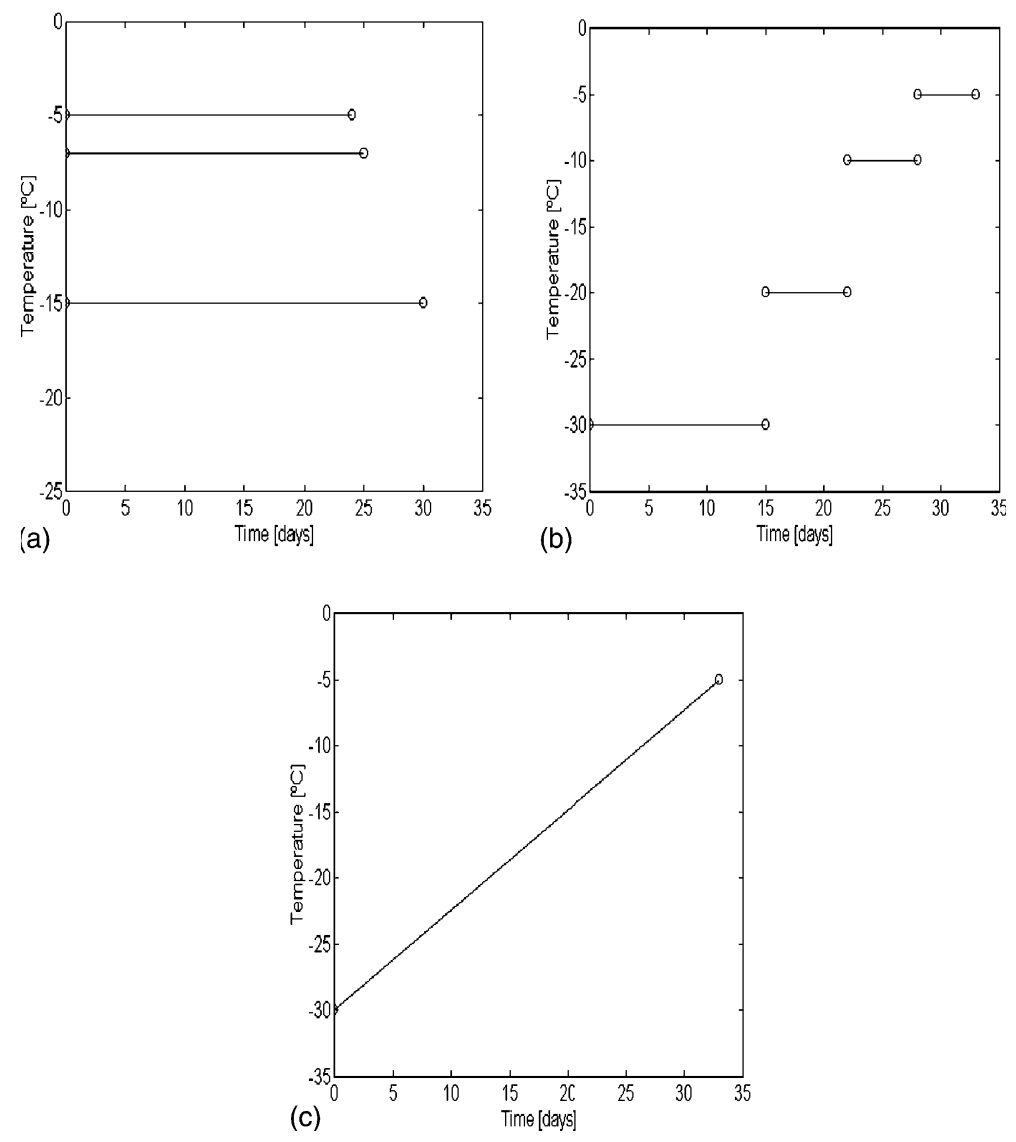

Fig. 3. Accelerated life testing designs: (a) design I, (b) design II, and (c) design III.

The studentised effect $\left(\beta_{i} / s\left\{\beta_{i}\right\}\right)$ of each kinetic parameter was computed, to define its importance at a $5 \%$ confidence level (double sided $T$-test). The semi studentised residuals were examined for outlayers, randomness and tested for normality (Box et al., 1978), to assess the quality of the fitted kinetic models.

\section{Designs II and III}

The program developed for the analysis of design I was modified to optimise the same kinetics under dynamic temperature conditions. Under dynamic temperature conditions, Eq. (12) takes the form:

$c=c_{0} \cdot \exp \left(-k_{\text {ref }} \cdot \int_{0}^{t}\left[-\frac{E_{\mathrm{a}}}{R} \cdot\left(\frac{1}{u}-\frac{1}{u_{\text {ref }}}\right)\right] \cdot \mathrm{d} t\right)$

Thereafter, the same statistical analysis, as for design I, was performed.

\section{Comparison between designs}

The precision of the three different designs models estimates was evaluated by the regression standard error. The statistical significance of the different designs estimated model parameters was accessed by their studentised effect (Table 2).

The different designs were compared in terms of accuracy and precision. To access the model accuracy, the kinetic models in Table 1 were assumed as having the correct deterministic behaviour. Thus, each design model accuracy, was calculated by average absolute error between the correct 'deterministic' model and the regression estimate:

$\operatorname{Er}=\frac{\int_{0}^{t}\left|c-c_{\mathrm{d}}\right| \mathrm{d} t}{t}$

A multifactor ANOVA (with replication) was conducted to study the effect of the ALT design (I, II and III), storage temperature and activation energy, on the kinetics accuracy (Er). The mean absolute error (Er) was calculated for each of the factor levels presented in Table 3, assuming that green beans were stored inside a refrigerator, under isothermal storage (with the characteristic temperature fluctuations). The study was performed for four storage temperatures (between -30 and $-5{ }^{\circ} \mathrm{C}$ ), and considering three $E_{\mathrm{a}}$ values, at minimum, intermediate and maximum levels, respectively, for AA $\left(3.861 \mathrm{~kJ} \mathrm{~mol}^{-1}\right)$, total vitamin $\mathrm{C}\left(42.01 \mathrm{~kJ} \mathrm{~mol}^{-1}\right)$ and 
Table 2

Regression statistical results of designs I, II and II

\begin{tabular}{|c|c|c|c|c|}
\hline Quality parameter & Design & Ascorbic acid $\left(\mathrm{mg} 100 \mathrm{~g}^{-1}\right)$ & Vitamin $\mathrm{C}\left(\mathrm{mg} 100 \mathrm{~g}^{-1}\right)$ & Flavour difference $(\%)$ \\
\hline \multirow[t]{3}{*}{$c_{0}$} & I & $146.5 \pm 0.333$ & $145.5 \pm 0.187$ & $99.14 \pm 0.267$ \\
\hline & II & $145.1 \pm 0.564$ & $146.1 \pm 0.311$ & $99.99 \pm 0.216$ \\
\hline & III & $145.0 \pm 0.693$ & $145.9 \pm 0.338$ & $100.5 \pm 0.244$ \\
\hline \multirow[t]{3}{*}{$k_{\text {ref }} \times 10^{-2}\left(\right.$ day $\left.^{-1}\right)$} & I & $16.59 \pm 0.056^{\mathrm{a}}$ & $5.868 \pm 0.007^{\mathrm{a}}$ & $23.12 \pm 0.012^{\mathrm{a}}$ \\
\hline & II & $15.27 \pm 0.624^{b}$ & $3.212 \pm 0.019^{\mathrm{b}}$ & $4.494 \pm 0.064^{b}$ \\
\hline & III & $15.76 \pm 0.335^{\mathrm{b}}$ & $3.215 \pm 0.017^{\mathrm{b}}$ & $4.507 \pm 0.037^{\mathrm{b}}$ \\
\hline \multirow[t]{3}{*}{$E_{\mathrm{a}}\left(\mathrm{kJ} \mathrm{mol}^{-1}\right)$} & I & $3.602 \pm 0.274$ & $40.13 \pm 0.127$ & $115.0 \pm 0.069$ \\
\hline & II & $3.193 \pm 1.476$ & $41.97 \pm 0.621$ & $117.5 \pm 1.557$ \\
\hline & III & $4.574 \pm 1.134$ & $42.04 \pm 0.851$ & $115.5 \pm 1.411$ \\
\hline \multirow[t]{3}{*}{ SE } & I & $8.379 \pm 0.339$ & $9.258 \pm 0.946$ & $9.304 \pm 0.699$ \\
\hline & II & $8.494 \pm 0.203$ & $7.555 \pm 1.488$ & $8.833 \pm 0.353$ \\
\hline & III & $8.974 \pm 0.258$ & $8.106 \pm 0.666$ & $8.529 \pm 0.167$ \\
\hline
\end{tabular}

\footnotetext{
${ }^{\mathrm{a}} u_{\text {ref }}=-7{ }^{\circ} \mathrm{C}$.
}

${ }^{\mathrm{b}} u_{\text {ref }}=-15^{\circ} \mathrm{C}$.

Table 3

Absolute error (Er) as function of temperature, $E_{\mathrm{a}}$ and ALT design

\begin{tabular}{lllll}
\hline \multirow{2}{*}{ Temperature $\left({ }^{\circ} \mathrm{C}\right)$} & $E_{\mathrm{a}}\left(\mathrm{kJ} \mathrm{mol}^{-1}\right)$ & Design & & III \\
\cline { 3 - 5 } & & $\mathrm{I}$ & $\mathrm{II}$ & $0.319 \pm 0.040$ \\
\hline-30 & 3.861 & $0.585 \pm 0.036$ & $0.084 \pm 0.008$ & $0.077 \pm 0.006$ \\
& 42.01 & $1.821 \pm 0.137$ & $0.054 \pm 0.003$ & $0.203 \pm 0.012$ \\
-15 & 117 & $0.340 \pm 0.034$ & $0.007 \pm 0.001$ & $0.118 \pm 0.028$ \\
& 3.861 & $0.380 \pm 0.051$ & $0.474 \pm 0.028$ & $0.112 \pm 0.008$ \\
-10 & 42.01 & $1.779 \pm 0.135$ & $0.207 \pm 0.016$ & $0.739 \pm 0.056$ \\
& 117 & $1.515 \pm 0.149$ & $0.763 \pm 0.052$ & $0.478 \pm 0.031$ \\
-5 & 3.861 & $0.229 \pm 0.033$ & $0.205 \pm 0.012$ & $0.126 \pm 0.023$ \\
& 42.01 & $0.877 \pm 0.053$ & $0.587 \pm 0.05$ & $0.067 \pm 0.008$ \\
& 117 & $0.757 \pm 0.068$ & $0.986 \pm 0.062$ & $0.642 \pm 0.063$ \\
& 3.861 & $0.166 \pm 0.025$ & $0.219 \pm 0.025$ & $0.121 \pm 0.007$ \\
\end{tabular}

flavour $\left(117 \mathrm{~kJ} \mathrm{~mol}^{-1}\right)$ degradations, and the three ALT designs (I, II and III).

\section{Results and discussion}

\section{Regression analysis}

Table 2 presents the estimated kinetic parameters of designs I, II and III, for AA, total vitamin C and flavour. Fig. 4 presents vitamin $\mathrm{C}$ degradation during designs I, II and III.

All the model fittings in Table 2 are statistically valid. The fitted models passed the lack of fit test $(p>0.05)$ and the residuals adjust the normal probability plot properly. Furthermore, the regression parameters high studentised effect $\left(t\left(\beta_{i}\right)\right)$ reassure that all estimates are statistically meaningful, and describe the recorded data correctly.

\section{ALT design comparison \\ Model precision}

Data in Table 2 suggests that the regression parameters studentised effect is higher in design I than in designs II and III. Therefore, the one-step optimisation procedure, assuming constant storage temperature, has better precision in the estimated parameters than the optimisations in designs II and III.

Nevertheless, there are no differences between the designs in terms of the regression standard error (SE). Therefore, the models obtained by the different designs are very similar in terms of precision of their predictions. 


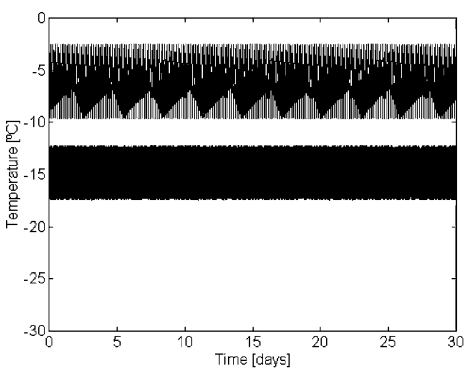

(a)

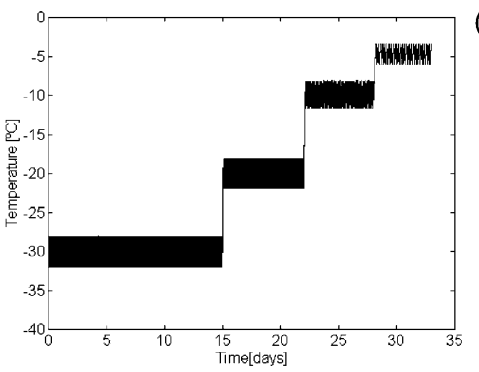

(b)
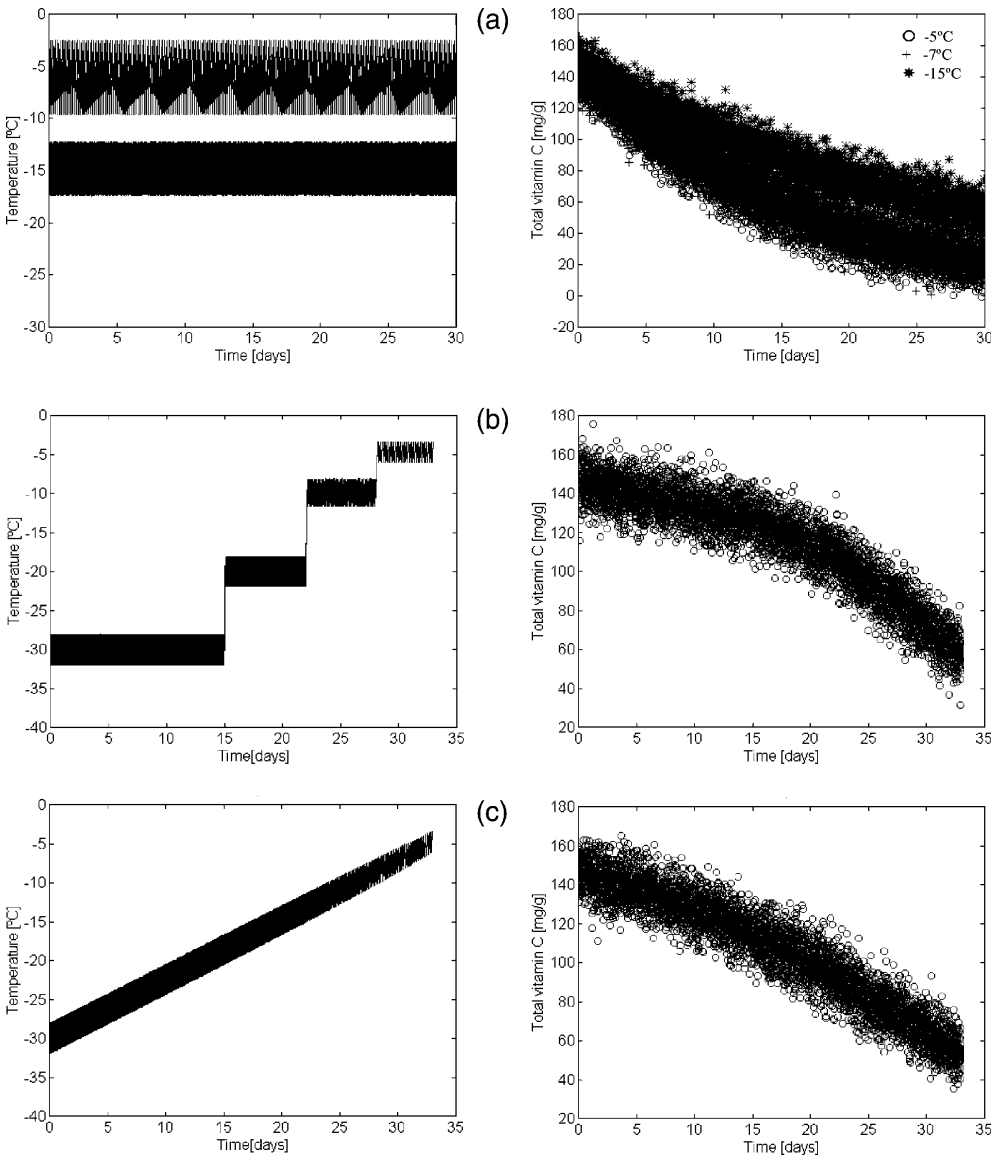

(c)

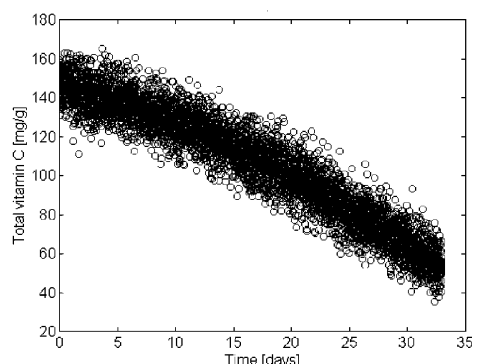

Fig. 4. Total vitamin C ALT tests results: (a) design I, (b) design II, and (c) design III.
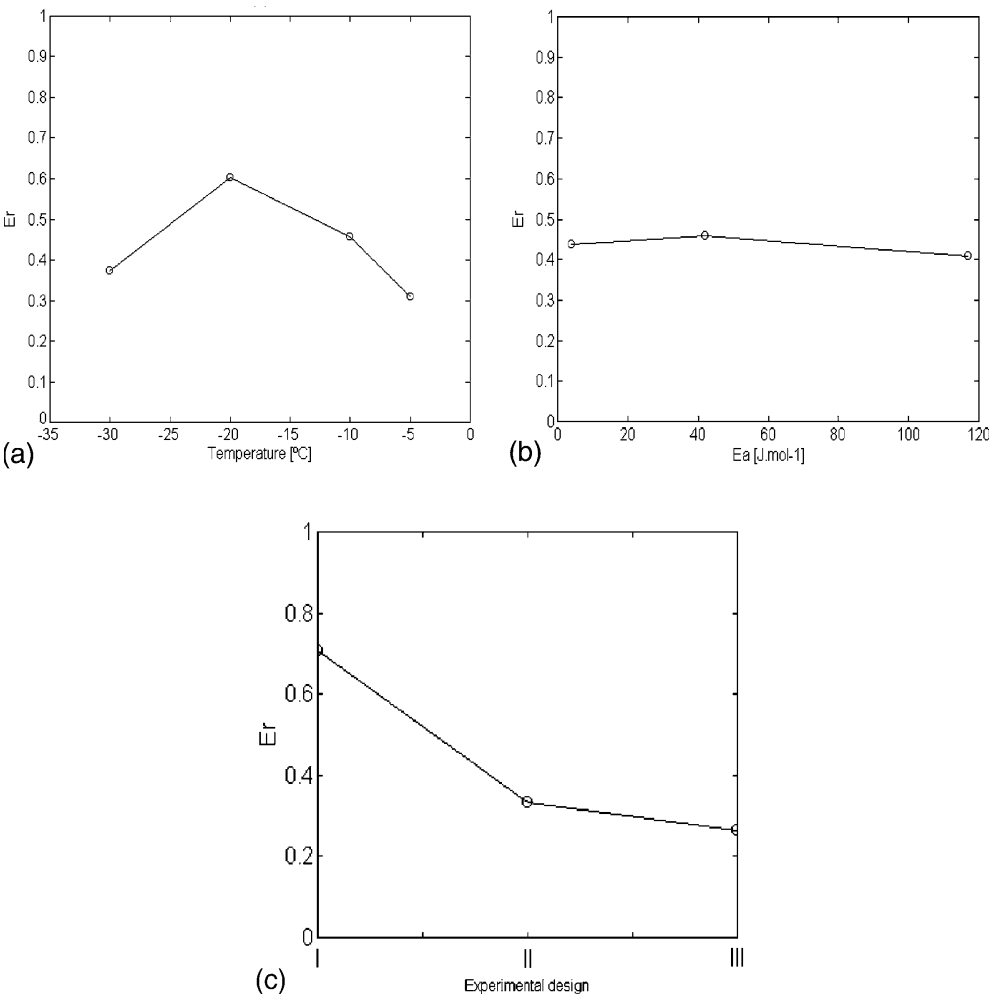

Fig. 5. Mean absolute error as function of (a) storage temperature, (b) activation energy and (c) experimental design. 


\section{Model accuracy}

The multifactor ANOVA lead to the conclusion that model accuracy has a strong dependency on the experimental design and activation energy, as well as their interactions.

Table 3 presents the absolute error (Er) of model prediction for the different designs, activation energies (corresponding to each quality attribute) and storage temperatures.

The multifactor ANOVA analysis of Table 3 data shows that all the studied factors are very significant in obtaining accurate estimates. However, the experimental ALT design has the highest $f$-value. Therefore, the experimental design is, in statistical terms, the most important factor in obtaining accurate models.

Fig. 5 shows the average factor effects on the absolute error. The average model absolute error shows parabolic pattern with storage temperature, with a maximum value at $-20^{\circ} \mathrm{C}$. The variation of the absolute error with the activation energy is not so abrupt, where the absolute error is around 0.45 .

However, the absolute error shows a great decrease between the design I and the dynamic ALT designs, which leads to a significant increase in model accuracy from the experimental design I to the designs II and III.

ALT tests showed that temperature inside refrigerators cannot be considered isothermal in kinetic terms. The time-temperature spectrum must be taken into account when deriving quality kinetics of frozen stored foods. Although the ALT tests simulated in this paper give excellent perspectives to the real experimental ones, the researcher must take into account that it is not possible to know a priori if the reaction mechanism will stay the same at the different temperatures. Events, such as increase in catalysts concentration, decrease in $\mathrm{pH}$, decrease of molecular mobility, the presence of other degradation compounds, may change the reaction pathway. Thus, preceding the kinetic study, it is necessary to perform the reaction chain network identification.

Thus, if the reaction kinetics remains unchanged, the ALT methodologies prove to be very efficient experimental designs to derive kinetic data.

\section{Conclusions}

All ALT methods were a good tool for obtaining frozen foods quality loss kinetics, once the degradation mechanisms are well known. The experimental designs II and III are more accurate than the generally used accelerated method, the design I. Design III attained better accuracy than design II, however it is more difficult to implement.

Temperature inside freezers can not be considered as isothermal conditions in terms of kinetics. Temperature fluctuations inside freezers influence the accuracy of the estimated models, and if this effect is taken into account, a significant accuracy increase is obtained in the model estimates.

\section{Acknowledgements}

The author R.C. Martins gratefully acknowledges his $\mathrm{PhD}$ grant (PRAXIS XXI BD/18541/98) to the Fundação para a Ciência e Tecnologia (FCT), Portugal.

\section{References}

Almeida, M., \& Martins, R. (2001). Installation of a beowulf class cluster over linux mandrake 7.1. URL: http://biotec. serveftp. org/.

Arabshahi, A., \& Lund, D. (1985). Considerations in calculating kinetic parameters from experimental data. Journal of Food Process and Engineering, 7, 239-251.

Barton, J., \& Nackman, L. (1991). Scientific and engineering C++: An introduction with advanced techniques and examples (5th ed.). Reading, Massachusetts: Addison-Wesley.

Bates, D., \& Watts, D. (1988). Non-linear regression analysis and it's applications. New York: John Wiley \& Sons.

Box, G., Hunter, W., \& Hunter, J. (1978). Statistics for experimenters. New York: Wiley.

Braess, D. (1997). Finite elements theory, fast solvers, and applications in solid mechanics. Cambridge: Cambridge University Press.

Brandão, T. R. S., \& Oliveira, F. A. R. (1997). The influence of the temperature increase rate on the accuracy of diffusion parameters estimate under non-isothermal conditions. International Journal of Food Science and Technology, 32, 63-72.

Frias, J. (1998). The development and application of product history indicators (PHI) for optimising product quality in drying process. $\mathrm{PhD}$ thesis, Escola Superior de Biotecnologia, Universidade Católica Portuguesa, Porto, Portugal.

Geist, G., Beguelin, A., Dongarra, J., Jiang, W., Manchek, R., \& Sunderam, V. (1994). PVM: Parallel virtual machine, a user's guide and tutorial for networked parallel computing. Cambridge, Massachusetts: The MIT Press, URL: http://www. netlib.org/ pvm3/book/pvm-book. ps.

Ghanem, R. (1991). Stochastic finite elements: A spectral approach. New York: Springer-Verlag.

Giel, A. (1998). Temperature fluctuations in domestic freezers. In The preservation of frozen food quality and safety throughout the distribution chain-Porto Meeting, Plenary 5 (pp. 19-20).

Henwood, D., \& Bonet, J. (1996). Finite elements, a gentle introduction. London: Macmillan Press, Ltd.

Høyland, A., \& Rausand, M. (1994). System reliability theory: Models and statistical methods. New York: John Wiley \& Sons.

Labuza, T. (1982). Shelf-life dating of foods. Wesport, Connecticut: Food \& Nutrition Press.

Labuza, T. (2000). Home page. URL: http://fscnl. fsci.umn. edu/ted_labuza/tpl.html.

Labuza, T. P., \& Schimdl, M. K. (1985). Accelerated shelf-life testing. Food Technology, 39, 57-64, 134.

Martins, R. C., \& Silva, C. L. M. (2002). Modelling colour and chlorophyll's losses of frozen green beans (Phaseolus vulgaris L.). International Journal of Refrigeration, 25, 987-995.

Martins, R. C., \& Silva, C. L. M. (2003a). Kinetics of frozen stored green beans (Phaseolus vulgaris L.) quality changes: Texture, 
vitamin C, reducing sugars and starch. Journal of Food Science, 68(7), 2232-2237.

Martins, R. C., \& Silva, C. L. M. (2003b). Inverse problem methodology for thermal-physical properties estimation of frozen green beans. Journal of Food Science, doi:10.1016/j.foodeng.2003. 08.008 .

Meyers, S. (1998). Effective C++: 50 specific ways to improve your programs and designs. Reading, Massachusetts: Addison-Wesley.

Moreira, L. A., Oliveira, F., Silva, T., \& Oliveira, J. (1993). Development of a non-isothermal method for determination of diffusional parameters. International Journal of Food Science and Technology, 28, 575-586.

Neter, J., Kutner, M., Nachtsheine, C., \& Wasserman, W. (1996). Applied linear statistical models (4th ed.). Chicago: IRWIN.

Ozisik, M. (1994). Finite differences in heat transfer. London: CRC Press.

Pandit, S., \& Wu, S. (1983). Time series and system analysis with applications. Malabar, Florida: Krieger Publishing Company.

Ragnarsson, J. O., \& Labuza, T. P. (1977). Accelerated shelf-life testing for rancidity in foods - a review. Food Chemistry, 2, 291-308.

Ramaswamy, H. S., \& Tung, M. A. (1981). Thermo-physical properties of apples in relation to freezing. Journal of Food Science, 46, 724-728.

Reid, D. (1999). Factors that influence the freezing process, an examination of new insights. In 20th International congress of refrigeration IIR/IIF Sydney, Australia.
Reid, D., Kotte, K., \& Kilmartin, P. (1999). A new method for accelerated shelf-life prediction for frozen foods. In 20th International congress of refrigeration, IRR/IIF, Sydney.

Rhim, J. W., Nunes, R. V., Jones, V. A., \& Swartzel, K. R. (1989a). Determination of kinetic parameters using linearly increasing temperature. Journal of Food Science, 54, 446-450.

Rhim, J. W., Nunes, R. V., Jones, V. A., \& Swartzel, K. R. (1989b). Kinetics of colour change of grape juice generated using linearly increasing temperature. Journal of Food Science, 54, 776-777.

Schwartzberg, H. G. (1976). Effective heat capacities for freezing and thawing of food. Journal of Food Science, 41, 153.

Schwartzberg, H. G. (1981). Mathematical analysis of the freezing and thawing of foods. In Tutorial presented AIchE summer meeting, Detroit, Michigan.

Segerlind, L. (1984). Applied finite element analysis (2nd ed.). New York: Macmillan Press, Ltd.

Shashkov, M. (1996). Conservative finite-difference methods on general grids. London: CRC Press.

Tong, H. (1994). Non-linear time series: A dynamical system approach. New York: Oxford University Press.

Veldhuizen, T. (1999). Blitz++ user's guide. URL: http: //o onumerics.org/blitz/BLITZ++.ps.

Waletzko, P., \& Labuza, T. P. (1976). Accelerated shelf-life testing of an intermediate moisture food in air and in oxygen-free atmosphere. Journal of Food Science, 41, 1338-1344. 